EDUCATION

Research, Innovation and Solutions on-line ${ }^{6}$
Electronic Journal of Research in Educational Psychology

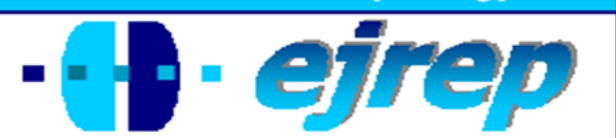

\title{
Elementary Students' Understanding of the Equal Sign in Number Sentences
}

\section{Marta Molina, Encarnación Castro \& Enrique Castro}

Departamento de Didáctica de la Matemática, Universidad de Granada, Granada

\section{Spain}

Marta Molina, Departamento de Didáctica de la Matemática, Universidad de Granada, Campus de Cartuja s/n, 18071, Granada. Spain. E-mail: martamg@ugr.es

(C) Education \& Psychology $\mathrm{I}+\mathrm{D}+\mathrm{i}$ and Editorial EOS (Spain) 


\begin{abstract}
Introduction. Moved by our interest in the curricular proposal of integrating algebraic thinking in elementary mathematics, we analyse the understanding of number sentences of a group of elementary students and its evolution when working on solving open and true/false number sentences.
\end{abstract}

Method. We developed a teaching experiment with a group of eight-nine years old students which shares the features of design research. It consisted of six one-hour in-class sessions, over a period of one year, in which we proposed students individual written activities, whole group discussions and individual interviews.

Results. Students evidenced four different meanings of the equal sign which are here used to establish different levels in their understanding. By using these levels, we analyze the evolution of students' understanding of the sentences along the experiment.

Discussion. Students evidenced the use of multiplicity of meanings of the equal sign and some displayed some instability in their understanding along the six sessions. The specific factors that explain that instability are identified and some didactical consequences are obtained. The obtained results are contrasted with those of previous studies.

Keywords: Early-Algebra; Equal sign; Equality; Number sentences; Relational thinking; Understanding.

Received: 11/27/08 Initial Acceptance: 11/29/08 Final Acceptance: 01/23/09 


\section{Resumen}

Introducción. Movidos por nuestro interés en la propuesta curricular de integración del pensamiento algebraico en las matemáticas de educación primaria, analizamos la comprensión de igualdades y sentencias numéricas de un grupo de estudiantes de primaria y su evolución cuando trabajan en la resolución de igualdades abiertas y sentencias numéricas verdaderas y falsas.

Método. Se llevó a cabo un experimento de enseñanza, con un grupo de estudiantes de entre ocho y nueve años, que comparte las características de la investigación de diseño. Consiste en seis sesiones de una hora, a lo largo de un año, en las que se propuso a los estudiantes actividades escritas individuales, discusiones de gran grupo y entrevistas individuales.

Resultados. Los estudiantes pusieron de manifiesto cuatro significados diferentes del signo igual los cuales empleamos aquí para distinguir niveles en su comprensión. Estos niveles nos permiten analizar la evolución de la comprensión de las igualdades y sentencias numéricas, por parte de los estudiantes, a lo largo del experimento.

Discusión. Los estudiantes emplearon multiplicidad de significados del signo igual y algunos mostraron cierta inestabilidad en su comprensión a lo largo de las seis sesiones. Identificamos los factores específicos que explican esta inestabilidad y extraemos algunas consecuencias didácticas. Los resultados obtenidos son contrastados con los de estudios previos.

Palabras clave: Comprensión; Early-Algebra; Igualdad; Pensamiento relacional; Sentencias numéricas; Signo igual.

Recibido: 27/11/08 Aceptación inicial: 29/11/08 Aceptación final: 23/01/09 


\section{Introduction}

In the later 80s, Davis (1985) and Vergnaud (1988) argued the need to start, at elementary education, a thought exploration of algebraic ideas in order to prepare students for facing the epistemological aspects involved in the transition from arithmetic to algebra. Later at 2001 these ideas, further developed, were brought to discussion at a PME Forum Research. Since then, there has been a growing interest of the mathematics education research community on analyzing and promoting the integration of algebraic thinking in the elementary curriculum.

At that PME meeting some opposed views emergued which are still present in current research: Does all algebra activity need to involve standard algebraic notation? Should changes in students' thinking be promoted through the use of tools such as notations and diagrams that may allow them to operate at a higher level of generality? Or, however, should the focus be in promoting the development of algebraic aspects currently presence at children's thinking? Other differences can be detected among researchers in relation to which types of tasks are considered algebraic, which types of evidences are considered necessary to assess the presence of algebraic thinking and which pedagogical approaches and teacher development should be promoted (Carraher y Schliemann, 2007).

Recognizing the various perspectives that coexist in the literature, we adopt a broad conception of algebra which includes the study of functional relations, the study and generalization of patterns and numeric relations, the study of structures abstracted from computation and relations, the development and manipulation of symbolism, and modelling as a domain of expression and formalization of generalizations (Kaput, 1998). From this view, the aim of this curricular proposal, named Early-Algebra, is not only to facilitate the later learning of algebra, but also to foster students' conceptual development of deeper and more complex mathematics from very early ages (Blanton \& Kaput, 2005; Kaput, 1998).

Previous research has analyzed the potential and feasibility of this proposal and have provided evidences that "when instruction is designed to build on children's mathematical ideas and to foster children's mathematical curiosity, children are likely to exhibit algebraic ways of thinking in the context of lessons in arithmetic, geometry, or measurement" (Bastable \& Schifter, 2008, p. 166). Particularly, it has been shown that students can:

- elaborate and express symbolically conjectures about basic arithmetic relations (Carpenter, Franke \& Levi, 2003), 
- think about arithmetic operations as functions, instead of as computations with particular numbers (Schliemann, Carraher, Brizuela, Earnest, Goodrow, Lara-Roth, S. et al., 2003),

- work with functional relations and use algebraic symbolism to express them (Carraher, Schliemann \& Brizuela, 2000),

- use algebraic representations such as graphic, tables and equations to solve problems (Brizuela \& Schliemann, 2003),

- represent and analyze problems which involve unknown quantities in both sides of an equation by using occasionally letters to represent those quantities (Brizuela \& Schliemann, 2003).

The difficulties that students display in the learning of algebra such as a limited understanding of the equal sign, erroneous conceptions about the meaning of letters used as variables and the reject of non-numeric expressions as answers to a problem have been previously considered consequence of the inherent abstraction of algebra and of limitations in students' cognitive development (Schliemann et al., 2003). However, within the Early Algebra proposal, researchers (e.g., Blanton \& Kaput, 2005; Brizuela \& Schliemann, 2003; Fujii, 2003) suggest that most students' difficulties with algebra may be due to the way they have been taught. Some studies as those above referred support this claim in relation to certain topics and ways of thinking by providing evidences of elementary students' capacity to use algebraic ways of thinking as well as to learn and understand basic algebraic notions.

Regarding the understanding of the equal sign - an important element in the use of mathematical language in general, and algebraic and arithmetic symbolism in particular-, we have observed (Castro \& Molina, 2007; Molina \& Ambrose, 2008) that although elementary students initially tend to interpret the equal sign as an operational symbol (i.e. a do something sign) if teaching is designed to promote a relational understanding of this symbol in the context of solving, building and discussing about number sentences, they are able to develop this understanding. As a continuation of that study, here we further explore elementary students' understanding of number sentences through the analysis of the equal sign meanings evidenced by a group of elementary students along a teaching experiment of six sessions. We describe the multiplicity of meanings for this symbol that students evidenced and analyze how they coexisted. We also discuss the elements that interfered or influenced students' understanding and its evolution. 
Although in this paper we focus in a component of arithmetic and algebraic notation, the equal sign, this does not imply that we consider working with algebraic expressions as a requisite for algebraic activity. We chose the context of number sentences moved by our interest of promoting students' development of algebraic thinking. This type of representations seems to invite and support discusión about numbers, operations and their properties better than other representations (Resnick, 1992). We are interested in promoting the development of students' recognition and verbalization of structure in this arithmetic context through the observation of patterns. A later step can be to produce the symbolic expression of the noticed relations (see Carpenter et al., 2003). By using this horizontal language, we also aim to help students advance in their recognition of the conventions used in algebraic symbolism.

Before describing the particularities of the teaching experiment developed, we briefly comment on various meanings of the equal sign that have been identified in the context of school arithmetic and algebra and summarize relevant previous studies.

\section{Meanings of the equal sign in school arithmetic and algebra}

The equal sign appeared in 1557 in Recorde's book "The Whetstone of Witte" (Cajori, 1993) and was universally accepted to express equality after its use by Leibniz (1646-1716) in his notation for calculus (Stallings, 2000). Nowadays this symbol is not only used to express equality and, when it is so, its meaning depends on the domain to which the objects belong (Freudenthal, 1994). As there is not a unique notion of equality in mathematics, the context is essential to determine its meaning. Occasionally things that are not equal such as the expressions $2 / 3$ and $4 / 6$ are considered so after defining an equivalence relation that includes both in a same class.

If we not only consider the recognized mathematical meanings of this symbol but also the meanings assigned by the students or in textbooks, this richness of meaning is higher. Here we pay attention to the meanings of the equal sign in the context of school arithmetic and algebra. We underline eleven different meanings of the equal sign ${ }^{1}$ which will later help us to explain students' understanding.

- Proposal of an activity: Meaning identified by Freudenthal (1994) which refers to the use of this symbol in incomplete expressions which contain a chain of numbers and/or symbols followed on the right by the equal sign (e.g., $16: 3=, x(x+1)-3 x(x+5)=$ ).

\footnotetext{
${ }^{1}$ See more information in Molina (2006).
} 
It is used to propose students a computation or simplification which may not be performed in a horizontal format.

- Operator (also known as the arithmetic or operational meaning of the equal $\operatorname{sign}^{2}$ ). It refers to the use of the equal sign to indicate the answer to a computation or the simplification of an expression which is written on its left (e.g., $4 \times 5=20$, $\left.x(x-2)+3 x^{2}=4 x^{2}-2 x\right)$. It is interpreted as an operator symbol; only readable from left to right.

- Expression of an action: a bidirectional meaning which extends the operator meaning by recognising the symmetric property of equality. It takes place in sentences with operational symbols in just one side of the equal sign, either right or left (e.g. $\left.2 x=x(x-2)-x^{2}+4 x, 24=12+12,12+12=24\right)$.

- "Splitter": Meaning given by students to this symbol when it is used to separate steps in an exercise (e.g., $\left.\sqrt{x^{2}+1}=\sqrt{x}=x^{2}+1=x=x^{2}-x+1=0, \mathrm{f}(\mathrm{x})=\mathrm{x}^{2}=\mathrm{f}^{2}(\mathrm{x})=\mathrm{x}^{4}\right)$. The steps linked may not be related.

- Expression of equivalence: It takes place when the equal sign is used to relate two representations of a same mathematical object. We distinguish three types of equivalences:

- Numerical equivalence: expression of sameness of numeric value of two arithmetic expressions (e.g., $4+5=3+6,3 x(4+2)=3 x 6,2 \sqrt{3}=\sqrt{12}$ ). The equal sign connects two representations of the same number. This meaning is referred as the relational meaning of the equal sign to contrast it with "the operational/arithmetic" meaning of this symbol.

- Symbolic equivalence: expression of sameness of numeric value of two algebraic expression for all values of the variable/s (e.g. $x^{2}+2 x=x(x-2)$, $a+b=b+a)$.

- Equivalence by definition or notation: expression of the equivalence of two arithmetic or algebraic expressions according to a defined equivalence relation

\footnotetext{
${ }^{2}$ As named by Rojano (2002) and Van Ameron (2002).
} 
or to the meaning of the notation in use (e.g., $\frac{3}{4}=\frac{6}{8}$ as fractions, $100 \mathrm{~cm}=1 \mathrm{~m}$, $\left.\frac{a}{b}=a b^{-1}\right)$

- Expression of a conditioned equivalence (equation). This meaning belongs to the context of algebra. It refers to the use of the equal sign to express an equivalence which is true for some or even none values of the variable/s contained in it (e.g, $\left.x^{2}+4 x=5 x-6\right)$.

- Expression of a functional or dependence relation. It refers to the use of the equal sign to express a dependence relation between variables or parameters (e.g., $l=2 \Pi r$, $y=3 x+2)$.

- Indicator of a connection or correspondence: Non precise meaning of the equal sign which refers to its use between non-mathematical objects or between mathematical

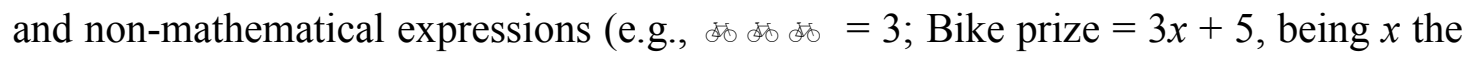
prize of a soccer ball).

- Indicator of an estimate: This meaning corresponds to the use of this symbol to relate an expression to an estimate of its numeric value (e.g., $1 / 3=0.33$ ).

- Definition of a mathematical object: The equal sign is used to define a mathematical object or to assign it a name (e.g., $a^{0}=1$ when $a$ is a natural number; $\mathrm{f}(\mathrm{x})=2 \mathrm{x}+3$ ).

- Assignment of numeric value: the equal sign is used to assign a numeric value to a symbol (e.g., If $\mathrm{x}=4$, which is the value of $x^{2}-5$ ?).

\section{Previous studies on the understanding of the equal sign}

In traditional mathematics education, along their arithmetic learning students tend to encounter and work on numbers in a vertical display. It is not till they start learning formal algebra that they are required to use horizontal language and, in particular, to use the equal sign to express equivalence between expressions (Pirie \& Martin, 1997). Students have encountered this symbol before (being used with several of the meanings above described) and have used it in number sentences. However, according to previous studies (Baroody \& Ginsburg, 1983; Behr, Erlwanger, \& Nichols, 1980; Carpenter et al., 2003; Kieran, 1981; Lindvall \& Ibarra, 1978; Molina \& Ambrose, 2008; Warren, 2003), they tend to see and use it as a "do something" signal. This operational conception may be consequence of their pre-symbolic 
arithmetic knowledge, the use of calculator or some cognitive limitations, but the procedural conception of arithmetic that students tend to develop in traditional arithmetic teaching is highlighted as the main factor.

According to the above referred studies, when students confront arithmetic expressions, they tend to focus on performing the operations expressed, usually by reading form left to right. They do not look at the expression as a whole neither they see number sentences as expressions of a relation but as some operations to perform and an answer. Students do not accept sentences of non-conventional ways (e.g., $\mathrm{a}=\mathrm{a}, \mathrm{c}=\mathrm{a} \pm \mathrm{b} \& \mathrm{a} \pm \mathrm{b}=\mathrm{c} \pm \mathrm{d}$ ) and, when they find difficulties in a sentence, they tend to combine the numbers in the way they consider more convenient according to the size of the numbers and to the operations involved - not to the structure of the sentence- So, students may operate all the numbers together or just those on one side of the equal sign, or they may repeat any of the numbers in the sentence. They also evidence the necessity of closure of expressions, that is, somewhere in the sentence they need to see the numeric value of the expressions.

This operational conception of arithmetic expressions, and of the equal sign, as well as the necessity of closure of expression are not usually challenged till students start learning algebra, and then, students show resistance to accept/adopt the equal sign as expression of equivalence (Byers \& Herscovich, 1977; Mevarech \&Yitschak, 1983). A careful introduction of the equal sign which considers its multiple meanings, particularly its meaning as expression of equivalence, is recommended by the above authors to diminish the students' cognitive resistance to accept this meaning and to ease the development of their understanding of the equal sign.

\section{Method}

The data presented in this paper come from a teaching experiment (Molina, Castro \& Castro, 2007; Steffe \& Thompson, 2000) which shares the features of research design as identified by Cobb and his colleagues (Cobb, Confrey, diSessa, Lehrer \& Schauble, 2003). It is an explanative study with two broad objectives (a) to analyse the students' understanding of number sentences, particularly of the equal sign, and its evolution, and (b) to study the use and development of relational thinking that students display when being asked to determine the validity of addition and subtraction number sentences (Molina, 2006). The results presented in this paper are concerned with the first objective. 
The term relational thinking refers to students' recognition and use of relationships between elements in number sentences and expressions to construct their solving strategy (Carpenter et al., 2003; Molina, 2006; Stephens, 2006), what we recognize as a specific type of algebraic thinking. When using relational thinking, students consider sentences and expressions as wholes (instead of as processes to carry out step by step), analyze them, discern some details and recognize some relations, and finally exploit these relations to construct a solution strategy (In a broader context Hejny, Jirotkova \& Kratochvilova (2006) named this approach as conceptual meta-strategies).

\section{Participants}

We worked with a class of $26^{3}$ eight-nine year old Spanish students (12 male and 14 females) from a state school in the region of Granada (Spain). Three of the students received extra support in mathematics at school. The selection of this group of students was due to its availability to participate in the study.

The students were not used to work with number sentences with operational signs in both sides, but sometimes they used to encounter this type of sentences in their textbook in activities or explanations regarding the use of brackets (e.g., $5+(6+8)=(5+6)+8)$, various addends computations (e.g. $12+8+10=20+10=30$ ) or an arithmetic property (e.g., $127+$ $48=48+127)$. The official teacher was especially concerned about the meaning of mathematical symbols and used to emphasize it in his daily teaching. Therefore we expected some students may display the numerical equivalence meaning. Relational thinking was not promoted in their regular instruction. Only some mental computation strategies were addressed. They were presented to the students as "tricks" and their use was not promoted in daily computation practice.

\section{Instruments}

We worked with the students along six one-hour in-class sessions, over a period of one year. The second session was two months after the first one. The sessions two, three, four and five were from one to two weeks apart. The final session was a written test at the beginning of the next academic course (eight months later). This timeline was chosen intentionally (except for vacation periods) because we wanted (a) the intervention to have a longer effect, (b) to

\footnotetext{
${ }^{3}$ The results will only refer to twenty-five students, as one student only attended session 1 and 4 , and he did not solve the activities of session 4 .
} 
reduce the probability of assessing a memory-based learning and, (c) to have sufficient time to analyze the data of each session and take decisions about the next in-class intervention.

We proposed the students missing-number and true/false number sentences - that is closed sentences which may be true or false (e.g. $27-14+14=26,78-45=77-44)-$ in individual written activities, whole group discussions and individual interviews. We chose these various formats of interventions because we wanted to (a) provide time for individual working and reflection, (b) promote students' exchange and comparison of ideas, and (c) have opportunities to closely access some students' thinking.

The proposed sentences included numbers using one, two or three digits and the operations of addition and subtraction. Some were sentences with all the operations included in one side of the equation (e.g., $100-94+94=100, \square=25-12$ ), that is action sentences ${ }^{4}$, where the equal sign is mostly interpreted as indicating the answer to the computation on its left side (Behr et al., 1980). Others were non-action sentences, that is sentences with no operational symbols (e.g., $12=12$ ) or which contain operational symbols in both sides of the equal sign (e.g. $14+6=10+10$ ). The sentences were based on the following arithmetic properties:

- commutative property of addition (e.g., $10+4=4+10$ ),

- non-commutability of subtraction (e.g., $15-6=6-15)$,

- inverse relation of addition and subtraction (e.g., $100-94+94=100$; $27-14+14=26)$

- compensation relation (e.g., $13+11=12+12 ; 78-45=77-44$ ),

- $\quad$ unity element of addition (e.g., $0+325=326 ; 125-0=125$ ),

- $\quad$ inverse element (e.g., $100-100=1$ ),

- composition/decomposition relationships (e.g., $78-16=78-10-6$; $7+7+9=14+9)$ and

- relative size comparisons (e.g., $37+22=300 ; 72=56-14$ ).

Therefore, they could be solved by using relational thinking as well as by calculation. Due to the different objectives of each session (described below) missing-number number sentences were used in session 1 and part of session 2, and true/false sentences in the other sessions. Missing-number sentences have proved to be useful for revealing different conceptions and challenging children to reconsider their interpretations of the equal sign, while

\footnotetext{
${ }^{4}$ We used Behr et al. (1980) distinction between action and non-action sentences.
} 
true/false sentences help challenge students' computational mindset (Molina \& Ambrose, 2008).

Students were asked to complete missing-number sentences and to explain how they solved it. In the true/false sentences, they were asked to determine their truth status and to provide a justification for their answers ${ }^{5}$. In the discussions students were encouraged to articulate their strategies-so that everyone was exposed to a range of approaches, from the computational to the relational-, and to provide justifications when asked. Justifications of their responses were demanded to the students as a way to access their thinking, their ways of "seeing" the sentences, and to elicit their appreciation and verbalization of relations as well as the recognition of properties.

The first two sessions were directed to assessing and extending students' understanding of the equal sign and detecting spontaneous evidences of use of relational thinking. Due to these objectives, in session 1 we asked the students to solve individually a written task composed by the following missing-number sentences:

$$
\begin{array}{lll}
8+4=\square+5 & \square=25-12 & 14+\square=13+4 \\
13-7=\square-6 & \square+4=5+7 & 12+7=7+\square
\end{array}
$$

After this task, there was a plenary discussion about their answers and the way they got them. In this way students' conceptions about the equal sign and the strategies they used to solve the sentences started to become explicit.

In session 2 students solved individually a written task with the following missingnumber sentences which were designed to explore some of the difficulties evidenced by the students in the previous session and to examine the stability of students' understanding of the equal sign:

$$
\begin{array}{ll}
12-4=13-\square & \square-6=15-7 \quad 14-9=\square-10 \\
9-4=\square-3 & 17-\square=18-8
\end{array}
$$

After having a whole group discussion about these sentences which involved justifications on demand, students were asked to construct their own addition and subtraction sentences with operations on both sides. With this last task we wanted to (a) contrast our conjec-

\footnotetext{
${ }^{5}$ Along the paper, we will use the expression "to solve" a true/false number sentence to refer to the process of determining the truth status of the sentence and providing a justification for it.
} 
ture about each student's understanding of the equal sign (which was based on students' previous explanations to the sentences) by asking them to do an active use of this sign, and (b) to check if they had noticed the richness in relations of the proposed sentences-although all but two students had not yet evidenced relational thinking. Finally, in this session there was a short guided discussion of some students' sentences which we considered could lead to verbalizations of relational thinking:

$$
\begin{array}{lll}
15-15=0-0 & 10+120=100+20 & 11+11=11+11 \\
10+4=10+4 & 1000+100=0
\end{array}
$$

This discussion made explicit that some sentences could be solved without performing any operation.

From the third session on, we promoted students' use and display of relational thinking by encouraging the use of multiple ways of determining the truth value of a number sentence, asking them for ways of doing so without doing all the computations, and by showing a special appreciation of explanations based on relations. We did not promote the learning of specific relational strategies but the development of a habit of looking for relations, trying to help students make explicit and apply the knowledge of structural properties which they had from their previous arithmetic experience. Session 3, 4, 5 and 6 aimed to identify strategies used by the students when working on the sentences and to detect and analyze obstacles. Now we briefly describe the design of each of these sessions.

In session 3 we developed a plenary discussion with justifications on demand from the students' responses to being asked if the following statements were true or false:

$$
\begin{array}{llll}
72=56-14 & 13-5+5=13 & 7+7+9=14+9 & 10+4=4+10 \\
10-7=10-4 & 51+51=50+52 & 78-16=78-10-6 & 0+325=326 \\
24-24=0 & 15-6=6-15 & 7+3=10+3 & 37+22=300 \\
78-45=77-44 & 125-0=125 & 62-13+13=65 & 27-14+14=26 \\
100+94-94=100 & 93=93 & 19-3=18-2 & 7=12 \\
27-14+14=26 & 24-15=24-10-5 & 13+11=12+12 & 100-100=1 \\
231+48=231+40+8 & & &
\end{array}
$$


In the design of these sentences we balanced the inclusion of: (a) true and false sentences, (b) numbers lower than 30 and numbers from 50 to 326, (c) sentences based on each of the arithmetic properties before mentioned.

In session 4 students individually solved a written task consisting of true/false sentences similar to those used on session 3 (see the particular sentences considered in table 1). Students had to decide if the sentences were true or false, justify their decision and, if they considered the sentence false, to propose a correction.

In session 5 semi-structured interviews were conducted with half of the students. We chose them depending on the use of relational thinking evidenced in previous sessions. We selected two to three students from each of the following categories: (a) No use of relational thinking evidenced; (b) Use of relational thinking evidenced just occasionally; (c) Half use and half non-use of relational thinking evidenced; (d) Use of relational thinking evidenced in most sentences, (e) unclear behaviour. The aim of this session was to deepen on the study of students' use of relational thinking. We probed these students with true/false sentences which were different to the ones where they had evidenced use of relational thinking in previous sessions, but similar to the sentences considered in session 3. As before, they were asked to justify their answers.

Session 6 was an assessment session in which students were probed with the same individual written task used in session 4.

Along the six sessions, we did an exhaustive data collection as the considered methodology recommends. We collected students' individual written work in all sessions to inform our assessment of each student's thinking. In addition, we video recorded the whole-group discussions and audio recorded the interviews. These recordings were complemented with the researchers' field-notes about the in-class interventions as well as about the researchers' meetings.

\section{Procedure}

We individually analyzed each students' answer in each sentence and compared it to his/her responses to other sentences in the same session and in other sessions, as well as to other students' responses. This analysis combined data from students' written work and students' oral explanations in discussions and interviews.

To address the first objective of this teaching experiment, we analyzed: 
a) The meanings of the equal sign evidenced by the students through their answers and explanations. We took as reference the meanings of this symbol in school arithmetic that we identified in the literature review.

b) The way in which students combined the terms of the sentences to solve them. This second criterion attends to if the students ignored any of the terms or modified their disposition within the sentence (e.g., they interpreted the right side in the sentence $14-9=\square-10$ as $10-\square)$. This syntactic criterion allowed us to precise how students made sense of the sentences and to explore their knowledge about the conventions which regulate the writing and reading of number sentences and expressions.

\section{Data analysis and results}

We first describe the equal sign meanings identified in the students' productions. They are later used to stablish levels of understanding of the equal sign which allow us to analyze the students' understanding of this symbol and its evolution along the teaching experiment sessions.

\section{Equal sign meanings evidenced}

When analyzing the students' responses in all the sessions we detected the use of four different meanings of the equal sign: operator, expression of an action, numerical equivalence and numerical sameness. In table 1 we summarize and exemplify the type of responses that students provided in each type of sentence when making use of the two operational meanings operator and expression of an action. The information in this table show that when making efforts to understand the sentences and find out an answer, students ignored terms of the sentence, combined terms from different sides of the equal sign, computed together all the numbers in the sentence or read part of the sentence backwards.

Table 1. Type of responses associated to the operational meanings of the equal sign evidenced and examples.

\begin{tabular}{|c|c|c|c|c|c|c|c|c|}
\hline \multirow[b]{3}{*}{ Type of responses } & \multicolumn{4}{|c|}{ OPERATOR } & \multicolumn{4}{|c|}{$\begin{array}{c}\text { EXPRESSION OF } \\
\text { ACTION }\end{array}$} \\
\hline & $\begin{array}{r}\mathrm{Ac} \\
\text { sent }\end{array}$ & tion & $\begin{array}{l}\text { Non } \\
\text { Sen }\end{array}$ & $\begin{array}{l}\text { action } \\
\text { tences }\end{array}$ & $\begin{array}{r}\mathrm{A} \\
\text { sen }\end{array}$ & $\begin{array}{l}\text { tion } \\
\text { ences }\end{array}$ & $\begin{array}{r}\text { Non } \\
\text { sen }\end{array}$ & $\begin{array}{l}\text { action } \\
\text { ences }\end{array}$ \\
\hline & Left & Right & Both & None & Left & Right & Both & None \\
\hline Correct & $\mathrm{X}$ & & & & $\mathrm{X}$ & $X$ & & \\
\hline NR & & $X$ & $\mathrm{X}$ & & & & & \\
\hline
\end{tabular}




\begin{tabular}{|c|c|c|c|c|c|c|c|c|}
\hline \multirow[b]{3}{*}{ Type of responses } & \multicolumn{4}{|c|}{ OPERATOR } & \multicolumn{4}{|c|}{$\begin{array}{l}\text { EXPRESSION OF } \\
\text { ACTION }\end{array}$} \\
\hline & \multicolumn{2}{|c|}{$\begin{array}{c}\text { Action } \\
\text { sentences }\end{array}$} & \multicolumn{2}{|c|}{$\begin{array}{c}\text { Non action } \\
\text { Sentences }\end{array}$} & \multicolumn{2}{|c|}{$\begin{array}{c}\text { Action } \\
\text { sentences }\end{array}$} & \multicolumn{2}{|c|}{$\begin{array}{c}\text { Non action } \\
\text { sentences }\end{array}$} \\
\hline & Left & Right & Both & None & Left & Right & Both & None \\
\hline $\begin{array}{l}\text { Reject the sentence as it is and transform it in an ac- } \\
\text { tion sentence with the operations on the left side (e.g., } \\
\text { Replacing } 6+4+18=10+18 \text { by } 6+4+18=28 \text { ). }\end{array}$ & & $\mathrm{X}$ & $\mathrm{X}$ & $\mathrm{X}$ & & & $\mathrm{X}$ & $\mathrm{X}$ \\
\hline $\begin{array}{l}\text { Ignore one of the terms and consider only a part of the } \\
\text { sentence of the form } a \pm b=c \text { (e.g., Answering that } \\
53+41=54+40 \text { is false because } 53+41 \text { is not } 40 \text { ) }\end{array}$ & & & $\mathrm{X}$ & & & & $\mathrm{X}$ & \\
\hline $\begin{array}{l}\text { Ignore one of the terms and consider only a part of the } \\
\text { sentence of the form } c=a \pm b \text { (e.g., Answering } 17 \text { to the } \\
\text { sentence } 14+\square=13+4) \text {. }\end{array}$ & & & & & & & $\mathrm{X}$ & \\
\hline $\begin{array}{l}\text { Combine two of the terms in the sentences by inter- } \\
\text { preting the sentence from left to right, not respecting } \\
\text { the structure of the sentence and occasionally ignoring } \\
\text { some elements (e.g., answering } 1 \text { in } 9-4=\square-3 \text { because } \\
4-1=3 \text { ) }\end{array}$ & & $\mathrm{X}$ & $\mathrm{X}$ & & & & $\mathrm{X}$ & \\
\hline $\begin{array}{l}\text { Combine two of the terms in the sentences by inter- } \\
\text { preting the sentence from right to left (backwards), } \\
\text { ignoring some elements (e.g., answering } 1 \text { to the sen- } \\
\text { tence } 14-9=\square-10 \text { because } 10-1=9 \text { ) }\end{array}$ & & & & & & & $\mathrm{X}$ & \\
\hline $\begin{array}{l}\text { Compute all the numbers in the sentence together } \\
\text { (e.g., Answering } 26 \text { to the sentence } 12+7=7+\square \text { ) }\end{array}$ & & & $\mathrm{X}$ & & & & $\mathrm{X}$ & \\
\hline $\begin{array}{l}\text { Repeat one the terms (e.g., answering } 25 \text { to } \square=25 \text { - } \\
\text { 12). }\end{array}$ & & $\mathrm{X}$ & $\mathrm{X}$ & & & & $\mathrm{X}$ & \\
\hline $\begin{array}{l}\text { Build a chain of operations (e.g., Completing the sen- } \\
\text { tence } 8+4=\square+5 \text { as follows } 8+4=12+5=17 \text { ) }\end{array}$ & & & $\mathrm{X}$ & & & & $\mathrm{X}$ & \\
\hline
\end{tabular}

$\mathrm{O}=$ open sentence; $\mathrm{C}=$ closed sentence (true/false)

The third row refers to the side of the equal sign in which the operations appear within the sentence.

The numerical equivalence meaning leaded students to answer correctly non-action sentences (except for possible computational errors). For example, Felix and Felipe evidenced this meaning of the equal sign by explaining as follows the validity of the sentence $53+41=54+40$ : "True because $53+41=54+40$ is the same by just taking a number from one addend and adding it to the other", "True because it gives the same" (after having computed $53+41=94$ and $54+40=94)$.

The numerical sameness meaning refers to the use of the equal sign to express some resemblance or sameness between expressions, that is, to relate expressions in which various terms are repeated (e.g., $122+35-35=122,12-5=5-12 \& 4+7=7-4$ ) or expressions with similar structure ${ }^{6}$ (e.g., $17-7=18-8$ ). This meaning implies not considering important the relative position of the terms, the operational signs that relate them or, their position in relation to the equal sign. As examples of students responses evidencing this meaning of the

\footnotetext{
${ }^{6}$ Here we used the term structure to refer to what Kieran (1989) named surface structure of a numeric or algebraic expression: the disposition of the terms and operational signs regulated by the restrictions of the order of operations.
} 
equal sign, we highlight the sentences constructed by Miriam and Celia in session 2 (see figures 1 and 2) as well as their responses from session 4 and 6 in the sentences $6+4+18=10+18$ and $17-12=16-11$ (see below) in which they demanded the expressions in both sides to include the same numbers in order for the sentence to be true.

$6+4+18=10+18$ Miriam: "False because it is not done well", she proposed as correction $18=18$

Celia: "False because it would be $6+4$ and then $4+6$, and there it said $10+18 ”$.

$17-12=16-11 \quad$ Miriam: “False because $17-12$ is not $16-11$ ”, she proposed as correction $17=17$

Celia: "False because $17-12$ is not equal to $16-11$, it would be $11-$ 16 and then $16-11$ "

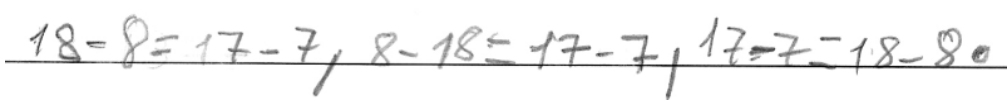

Figure 1. Sentences written by Miriam on session 2

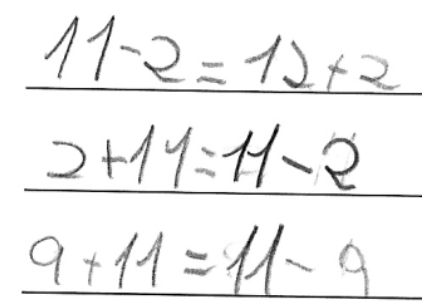

Figure 2. Sentences written by Celia on session 2

The numerical sameness meaning leaded students to consider true those sentences in which the same terms appeared several times — what we see as an over-generalization of the reflexive property of equality - or when they detected some resemblance between the expressions in both sides - by sometimes ignoring the operational symbols as well as the relative position of the terms and their position in relation to the equal sign-.

Table 2 shows the type of sentences which were built by students when making use of each of the meanings of the equal sign previously described. 
Table 2. Type of sentences constructed when evidencing each meaning of the equal sign

\begin{tabular}{|c|c|c|c|c|}
\hline \multirow{2}{*}{ Type of sentences constructed } & \multicolumn{3}{|c|}{ Equal sign meanings } \\
\cline { 2 - 5 } & \multicolumn{2}{|c|}{ Operational } & \multicolumn{2}{c|}{ Relational } \\
\cline { 2 - 5 } & $\mathrm{O}$ & $\mathrm{EA}$ & $\mathrm{NE}$ & $\mathrm{NS}$ \\
\hline Action sentences with operation on the left side & $\mathrm{X}$ & $\mathrm{X}$ & & \\
\hline Action sentences with operations on the right side & & $\mathrm{X}$ & & \\
\hline Non action sentences & & & $\mathrm{X}$ & \\
\hline Sentences that are a chain of operations & $\mathrm{X}$ & $\mathrm{X}$ & & \\
\hline Sentences with various terms equal or alike & & & & $\mathrm{X}$ \\
\hline
\end{tabular}

$\mathrm{O}=$ operator; $\mathrm{EA}=$ expression of an action; $\mathrm{NE}=$ numerical equivalence; $\mathrm{NS}=$ numerical sameness.

\section{Students' understanding}

By using any of these four meanings students made sense of the sentences proposed. In many occasions students used different meanings in a set of sentences depending on the characteristics of each sentence. For example, on session 2 César evidenced the expression of an action meaning in the sentences $8+4=\square+5 \& 14+\square=13+4$ by answering 17 in both cases $^{7}$, and the numerical equivalence meaning in at least one non-action sentence (he answered 12 to $13-7=\square-6)^{8}$.

Students accepted multiplicity of meanings for the equal sign and did not seem confused by the disconnection existing between them. Even in action sentences, sometimes students interpreted the equal sign differently depending on the operations involved - addition vs. subtraction - probably due to their lower mastery of subtraction. Students also tended to use an operational meaning of the equal sign whenever they encountered non-action sentences which were difficult for them in some way (e.g., due to the size of the numbers involved), despite having used the numerical equivalence meaning in other sentences. They also seemed to accept more than one solution for a same sentence.

Some students evidenced finding significant difficulties to make sense of action sentences with the operations on the right despite solving correctly action sentences with the operations on the left as well as non-action sentences. This fact suggests that the development of

\footnotetext{
${ }^{7}$ In $8+4=\square+5$ the 17 is result of adding all the numbers in the sentence, while in $14+\square=13+4$ it comes from adding the numbers on the right side of the equal sign, that is, it is the numeric value of the expression on the right side.
} 
the numerical equivalence meaning does not imply neither includes the development of the expression of an action meaning. The later is not a necessary step in the acquisition of understanding of the equal sign as the expression of equivalence.

\section{Levels of understanding of the sentences}

Having identified the meanings of the equal sign used by each student in each sentence, we distinguish three levels in the students' understanding of the sentences: operational, non-stable and advanced. In table 3 we describe each of these levels by specifying the meanings of the equal sign evidenced in each type of sentence.

Table 3. Correspondence between levels of understanding of the sentences and the meaning of the equal sign evidenced ${ }^{1}$

\begin{tabular}{|c|c|c|c|}
\hline \multirow[b]{2}{*}{ Level } & \multirow{2}{*}{$\begin{array}{l}\text { Non action } \\
\text { sentences }\end{array}$} & \multicolumn{2}{|c|}{ Action sentences } \\
\hline & & $\begin{array}{l}\text { Operations on the } \\
\text { right side }\end{array}$ & $\begin{array}{c}\text { Operations on the } \\
\text { left side }\end{array}$ \\
\hline $3^{\circ}$ Advanced understanding & $\mathrm{NE}$ & EA & $\mathrm{O}$ \\
\hline $2^{\circ}$ Non stable understanding & $\mathrm{NE}$ and (EA or $\mathrm{O})$ & EA or $\mathrm{O}$ & $\mathrm{O}$ \\
\hline $1^{\circ}$ Operational understanding & EA and/or O & EA or $\mathrm{O}$ & $\mathrm{O}$ \\
\hline
\end{tabular}

$\mathrm{O}=$ operator; $\mathrm{EA}=$ expression of an action; $\mathrm{NE}=$ numerical equivalence.

${ }^{1}$ In all the type of sentences considered, some students at different level in their understanding of the sentences evidenced the meaning numerical sameness.

According to table 3, students evidencing an advanced understanding of the equal sign solved correctly sentences of all the types considered (except for computation errors). For example we classify Jaime's understanding in session 1 as advanced because he solved correctly all the sentences we proposed them what included action sentences with the operations on the right side and non-action sentences (see table 4).

Table 4. Jaime's answers to open number sentences proposed on session 1

\begin{tabular}{|c|c|c|c|c|c|}
\hline $8+4=\square+5$ & $\square=25-12$ & $14+\square=13+4$ & $12+7=7+\square$ & $13-7=\square-6$ & $\square+4=5+7$ \\
\hline 7 & 13 & 3 & 12 & 12 & 8 \\
\hline
\end{tabular}

Students evidencing a non-stable understanding used an operational meaning of the equal sign as well as the numeric equivalence meaning, when working on non-action number sentences. Therefore they occasionally evidenced some difficulties in recognizing these sentences as expressions of relations. This is the case of Cesar in session 2 (see example in the previous section of this paper).

\footnotetext{
${ }^{8}$ His other responses to non-action sentences could be result of computational errors when using the numerical
} 
The last level of understanding corresponds to an operational conception of the equal sign which is evidenced by the use of both or just one of the operational meanings of this symbol: operator and expression of an action. In this case students did not solve correctly any non-action sentences. For example, Miguel's understanding in session 4 is classified as operational because he used the operator meaning of the equal sign in all the non-action sentences by demanding one of the numbers on the right side to be the numeric value of the expression on the left side (e.g., " [ $75+23=23+75]$ False because $75+23$ is not 75 nor 23 ”). In addition he showed this meaning in the action sentences considered but in these cases he successfully solved the sentences (e.g., "[ $75-14=340]$ False because 75 minus 14 is not $340 ”)$.

\section{Evolution of students' understanding}

We classified students' understanding of the sentences along the six sessions by using the above described levels (see table 5). In some occasions students' understanding could not be identified. For example, this is the case of Celia in session 4. Most of her responses were positive or negative "readings" of the sentence which she used to justify its truth or falseness as in the following explanations: "[122+35-35=122] False because 122 plus 35 minus 35 doesn't give 122”, “[16+14-14=36] True because $16+14$ minus 14 gives 36”. Analyzing the information in Table 5 we observe that:

- Fourteen students evidenced a stable advanced understanding of the sentences.

- Six students evidenced this level of understanding but with certain instability:

$\circ$ Felipe and Marcos showed an advanced understanding in all but one of the sessions. Their instability was caused by subtraction sentences considered in session 2 which were significantly more difficult for most of the students.

- Miriam and Blanca displayed this level in the firsts and lasts sessions. Their participation in session 3 was scarce, so it was impossible to identify their understanding. Our intervention encouraging the use of relational thinking had a negative effect in their understanding. Both students may had found difficulties in understanding relational solving strategies and, therefore, got confused about the meaning of the equal sign. This conjecture is supported by the computational tendency that they both displayed in their approach to all the sentences. 
Cesar and Manuel evidenced an advanced understanding in the intermediate sessions. Both students displayed low arithmetic skills from the first session but fully engaged in the proposed activities. Our interventions may have helped them to develop their understanding although not enough for it to get stable.

Table 5. Students' level of understanding evidenced in each session

\begin{tabular}{|c|c|c|c|c|c|c|c|}
\hline & \multirow[t]{2}{*}{$\begin{array}{l}\mathrm{S} 1 \\
\mathrm{~N}=26\end{array}$} & \multicolumn{2}{|c|}{$\begin{array}{c}\mathrm{S} 2 \\
\mathrm{~N}=\mathbf{2 1}\end{array}$} & \multirow[t]{2}{*}{$\begin{array}{r}\mathrm{S} \mathrm{3} \\
\mathrm{N}=22\end{array}$} & \multirow[t]{2}{*}{$\begin{array}{c}\mathrm{S} \mathrm{4} \\
\mathrm{N}=25\end{array}$} & \multirow[t]{2}{*}{$\begin{array}{c}S 5 \\
N=13\end{array}$} & \multirow[t]{2}{*}{$\begin{array}{c}S 6 \\
N=25\end{array}$} \\
\hline & & Part I & Part II & & & & \\
\hline \multicolumn{8}{|l|}{ Felipe } \\
\hline Felix & & & & & NS & & \\
\hline \multicolumn{8}{|l|}{ Roberto } \\
\hline \multicolumn{8}{|l|}{ Marcos } \\
\hline Ruben & & & & & NS & & \\
\hline \multicolumn{8}{|l|}{ Miguel } \\
\hline Cesar & & & & & & & NS \\
\hline \multicolumn{8}{|l|}{ Clara } \\
\hline \multicolumn{8}{|l|}{ Rocio } \\
\hline \multicolumn{8}{|l|}{ Merche } \\
\hline Jose & & & & & & ¿NS? & \\
\hline \multicolumn{8}{|l|}{ David } \\
\hline Belén & & & & ¿NE ó NS? & NS & & \\
\hline \multicolumn{8}{|l|}{ Elena } \\
\hline \multicolumn{8}{|l|}{ Carmen } \\
\hline Miriam & & NS & ¿NS? & & NS & & \\
\hline \multicolumn{8}{|l|}{ Jaime } \\
\hline \multicolumn{8}{|l|}{ Noelia } \\
\hline Javier & ¿NE? & & & & NR & & NR \\
\hline \multicolumn{8}{|l|}{ Manuel } \\
\hline Beatriz & & & & NR & & & \\
\hline \multicolumn{8}{|l|}{ Maite } \\
\hline \multicolumn{8}{|l|}{ Violeta } \\
\hline Celia & & & NS & & & & $\mathrm{NS}$ \\
\hline \multicolumn{8}{|l|}{ Blanca } \\
\hline Ester & & & & & & & \\
\hline
\end{tabular}

- Rocio and Beatriz showed a progression in their understanding and finally reached an advance understanding. In their case our intervention was enough for them to develop a stable understanding of the sentences.

- Miguel regressed in his understanding during the six sessions. As happened with Miriam and Blanca, our intervention encouraging the use of relational thinking had a negative effect in his understanding. 
- Noelia's understanding was irregular. This instability in her understanding is associated to specific difficulties she encountered in particular sentences due to the operations, the size of the numbers involved or the position of the unknown term. She also required more time than her partners to solve each sentence what suggest lower arithmetic mastery.

In each session almost half of the students evidenced an advanced understanding and four or five students' understanding varied. In session 1, 4 and 6 about 20 of the 26 students displayed an advanced understanding while in session 2 and 3 this number decrease. In session 3 this may be due to the fact that the understanding of eight students could not be precise due to their scarce or none participation in the discussion. In session 2, however, it seems result of the higher number of difficulties that students encountered in subtraction sentences what led them to use operation meanings of the equal signs in all the sentences.

The numerical sameness meaning was (occasionally) evidenced by the students in all type of sentences considered, while displaying any of the level of understanding previous described. The extreme cases were those occasions in which students forced action sentences to included repeated numbers. This relational meaning was shown by seven students along the six sessions (see Table 5). Initially we though it could be a step in the development of an advanced understanding of the equal sign because it implies the acceptation of sentences as expression of a relationship. However, the analysis of the various manifestations of this meaning show that it is not related to any specific level of understanding as four students evidenced it together with the numerical equivalence meaning, others with an operation meaning of the equal sign, and the rest did not clearly display the meaning they were using in most sentences.

\section{Discussion}

According to previous studies, students tend to interpret the equal sign as an operational symbol and are reluctant to adopt or develop the numerical equivalence meaning. However, most students at our study evidenced the used of this meaning from the beginning and fourteen of them used it in a stable way along the different sessions. In general, students displayed awareness of the necessity of taking into account all the terms within the sentence and only two students evidenced difficulties in the sentence $\square=25-12$ due to its least conventional form.

These differences with other studies are probably due to the teaching received by these students. His official teacher considered the meaning of mathematical symbols and its role in 
mathematical language very important. However, some students displayed instability in their understanding especially when the sentences involved computations which required a higher cognitive demand or which caused them some difficulties. It was then when they altered the structure of the sentence or ignored some of the terms. These results confirm the necessity to promote the understanding of the equal sign in a continuous way. Other students' instability was related to our special encouragement of the use of relational thinking. They displayed a computational tendency in their approach to the sentences which seemed to prevent them from understanding relational approaches and the numerical equivalence meaning of the equal sign.

We also observed that the students seemed to accept and possess various meanings for the equal sign. They used one or another meaning depending on the characteristics of the sentence and did not seem to be confused by the disconnection existing between these meanings. Even in action sentences sometimes students interpreted the equal sign differently depending on the operations involved (addition vs. subtraction). They also seemed to accept more than one solution for a sentence. The students' use of multiple meanings is supported by the fact that each of the three meanings operator, expression of an action and expression of equivalence is suitable in some types of sentences as well as by the richness of meanings usually given to this symbol in arithmetic teaching (as shown in this paper). From this perspective, the difficulty for students is then to recognize the structure of sentences corresponding to each meaning. So, occasionally four students used the meaning numerical equivalence to justify the truth or falseness of sentences of the form $a+b-b=c$ by operating pairs of numbers from different sides of the equal sign. For example, in the sentence $122+35-35=122$ Roberto subtracted $122-35$ and added $122+35$, and concluded that the sentence was false just by comparing the results of both computations. In addition, a student concluded that the sentence $7+5=10+6$ was false because $7+10$ is not the same than $10+5$. In this case the student used the meaning numerical equivalence but did not respect the structure of the sentence.

Considering these evidences as well as the required understanding for the later work with algebraic symbolism, we recommend addressing in teaching the connection existing between the various meanings of the equal sign, especially between the meanings operator, expression of an action and numerical equivalence in order to integrate them in the meaning numerical equivalence.

In a prior study (Molina \& Ambrose, 2008) we observed that elementary students tended to accept the expression of an action meaning before developing the meaning 
numerical equivalence. This operational meaning may be more easily adopted or developed by students, however, the results here described suggest that the numerical equivalence meaning does not imply the acceptance and understanding of all action number sentences (although theoretically it may seem that it does.) We also conclude that the expression of an action meaning is not a required step in the development of the numerical equivalence meaning for the equal sign and also that this latter meaning does not imply that students recognize the symmetric property of equality.

In addition to the meanings of the equal sign detected in previous studies, we here identified the meaning numerical sameness. It is slightly imprecise and is not adequate in mathematics, unlike the others meanings which are acceptable in some mathematical expressions. Taken to an extreme position, this meaning could lead to affirm that the sentence $23=32$ is true just because both sides include a three and a two. The use of this meaning may lead students to consider true sentences of the form $a+b-b=a, a+b=b-a$, $a+b=b+a, a-b=b-a \& a-b+b=a$ just by observing the repetition of terms within the sentence. This type of sentences can be used in the classroom to make explicit some of the conventions of mathematical written language which allow distinguishing between the previous sentences. When doing so, it is especially important to know what the students are attending to and whether they are ignoring any elements or characteristics of the sentence.

The numerical sameness meaning imply solving number sentences by using relational thinking but it is only based on aesthetic aspects, living aside the understanding of the operations or expressions involved and the equivalence expressed by the sentence. As a conclusion, we remark the necessity to emphasize in teaching the restriction implied by the equality relations. For this aim, the imprecise meanings of the equal sign are an obstacle as Carpenter et al. (2003) and Wheeler (1981) mention.

It is possible that the type of intervention we performed in the classroom favoured the development of the numerical sameness meaning as we encouraged students to attend to relations and to try to avoid computing as solving method and we used sentences based on arithmetic properties. Anyway, we have detected a students' belief that should be addressed in teaching: sentences including repeated numbers are true.

Finally, we highlight the main factors that influenced the students' understanding evolution: (a) The cognitive demand of the operations involved in the sentence and, therefore, the students' mastery of arithmetic operations and their number sense; (b) Students' structure sense (Hoch y Dreyfus, 2004, 2005) which includes the capacity to see and arithmetic or al- 
gebraic expression as a whole, to split an expression into sub-structures, to detect connections between the structures of different expressions and to recognize in an expression a known structure; (c) Students' knowledge of conventions of mathematic language (e.g., 10 - $\square$ cannot be interpreted/read as $\square-10$, order of operations, etc.). All these elements should be considered when promoting the development of students' understanding of number sentences together with the richness of meanings usually attributed to the equal sign and the connections existing between them.

\section{Acknowledgments}

This study has been developed within a Spanish national project of Research, Development and Innovation, identified by the code SEJ2006-09056, financed by the Spanish Ministry of Sciences and Technology and FEDER funds.

\section{References}

Baroody, A. J. \& Ginsburg, H. P. (1983). The effects of instruction on children's understanding of the "equals" sign. The Elementary School Journal, 84(2), 199-212.

Bastable, V. \& Schifter, D. (2008). Classroom Stories: Examples of Elementary Students Engaged in Early Algebra. In J.J., Kaput, D. W. Carraher \& M.L. Blanton (Eds.), Algebra in the Early Grades (pp. 165-184). New York: Lawrence Erlbaum Associates.

Behr, M, Erlwanger, S., \& Nichols, E. (1980). How children view the equal sign. Mathematics Teaching, 92, 13-15.

Blanton, M. L. \& Kaput, J. (2005). Characterizing a Classroom Practice that Promotes Algebraic Reasoning. Journal for Research in Mathematics Education, 36(5), 412-446.

Brizuela, B. M. \& Schliemann, A. D. (2003). Fourth graders solving equations. In N. A. Pateman, B. J. Dougherty \& J. T. Zilliox (Eds.), Proceedings of the $27^{\text {th }}$ Conference of the International Group for the Psychology of Mathematics Education and the $25^{\text {th }}$ Conference of Psychology of Mathematics Education North America (Vol. 2, pp. 137144). Honolulu, HI: University of Hawaii.

Byers, V. \& Herscovics, N. (1977). Understanding school mathematics. Mathematics Teaching, 81, 24-27.

Cajori, F. (1993). A history of mathematical notations. New York: Dover Publications.

Carpenter, T. P., Franke, M. L., \& Levi, L. (2003). Thinking mathematically: integrating arithmetic and algebra in elementary school. Portsmouth: Heinemann. 
Carraher, D. W. \& Schliemann, A. D. (2007). Early algebra and algebraic reasoning. In F. K. Lester (Ed.), Second handbook of research on mathematics teaching and learning (pp. 669-705). Reston, VA: NCTM e IAP.

Carraher, D. W., Schliemann, A. D. \& Brizuela, B. M. (2000, october). Early algebra, early arithmetic: Treating operations as functions. Presented at the Twenty-second Annual Meeting of the North American Chapter of the International Group for the Psychology of Mathematics Education, Tucson, Arizona.

Castro, E., \& Molina, M. (2007). Desarrollo de pensamiento relacional mediante trabajo con igualdades numéricas en aritmética básica. Educación Matemática, 19(2), 67-94

Cobb, P., Confrey, J., diSessa, A., Lehrer, R. \& Schauble, L. (2003). Design experiment in Educational Research. Educational Researcher, 32(1), 9-13.

Davis, R. B. (1985). ICME-5 Report: Algebraic thinking in the early grades. Journal of Mathematical Behaviour, 4, 195-208.

Freudenthal, H. (1994). Fenomenológica didáctica de las estructuras matemáticas (Textos seleccionados). Traducción, notas e introducción de L. Puig. México D.F.: Cinvestav del IPN.

Fujii, T. (2003). Probing students' understanding of variables through cognitive conflict problems is the concept of a variable so difficult for students to understand? In N. Pateman, G. Dougherty \& J. Zilliox (Eds.), Proceedings of the $27^{\text {th }}$ Conference of the International Group for the Psychology of Mathematics Education and the $25^{\text {th }}$ Conference of Psychology of Mathematics Education North America (Vol. 1, pp. 49-66). Honolulu, HI: University of Hawaii.

Hejny, M., Jirotkova, D., \& Kratochvilova J. (2006). Early conceptual thinking. In J. Novotná, H. Moraová, M. Krátká \& N. Stehlíková (Eds.), Proceedings of the 30th Conference of the International Group for the Psychology of Mathematics Education (Vol. 3, pp. 289-296). Prague: Program Committee.

Hoch, M., \& Dreyfus, T. (2004). Structure sense in high school algebra: the effect of brackets. In M. Johnsen \& A. Berit (Eds.), Proceedings of the 28th International Group for the Psychology of Mathematics Education (Vol. 3, pp. 49-56). Bergen: Program Committee.

Hoch, M., \& Dreyfus, T. (2005). Students' difficulties with applying a familiar formula in an unfamiliar context. In H.L. Chick \& J.L. Vincent (Eds.), Proceedings of the 29th conference of the international group for the psychology of mathematics education (Vol. 3, pp. 145-152). Melbourne: PME. 
Kaput, J. (1998). Teaching and Learning a new algebra with understanding. Dartmouth, MA: NCISLA.

Kieran, C. (1981). Concepts associated with the equality symbol. Educational Studies in Mathematics, 12(3), 317-326.

Kieran, C. (1989). The early learning of algebra: a structural perspective. In S. Wagner \& C. Kieran (Eds.), Research issues in the learning and teaching of algebra (Vol. 4, pp. 3359). Reston, VA.: LEA \& NCTM.

Lindvall, C. M. \& Ibarra, C. G. (1980). Incorrect procedures used by primary grade pupils in solving open addition and subtraction sentences. Journal for Research in Mathematics Education, 11(1), 50-62.

Mevarech, Z. R. \& Yitschak, D. (1983). Students' misconceptions of the equivalence relationship. In Hershkowitz, Weizmann Institute of Science (Ed.), Proceedings of the Seventh International Conference for the Psychology of Mathematics Education (pp. 313-318). Rehobot, Israel.

Molina, M. (2006). Desarrollo de pensamiento relacional y comprensión del signo igual por alumnos de tercero de Primaria. Dissertation, University of Granada. Available at http://cumbia.ath.cx:591/pna/Archivos/MolinaM07-2822.pdf

Molina, M. \& Ambrose, R. (2008). From an operational to a relational conception of the equal sign. Thirds graders' developing algebraic thinking. Focus on Learning Problems in Mathematics, 30(1), 61-80.

Molina, M., Castro, E., \& Castro, E. (2007). Teaching Experiments within Design Research. The International Journal of Interdisciplinary Social Sciences, 2(4), 435-440

Pirie, S. \& Martin, L. (1997). The equation, the whole equation and nothing but the equation! One approach to the teaching of linear equations. Educational Studies in Mathematics, 34(2), 159-181.

Rojano, T. (2002). Mathematics Learning in the Junior Secondary School: Students' Access to Significant Mathematical Ideas. In L. D. English (Ed.), Handbook of International Research in Mathematics Education (pp. 143-163). Mahwak, NY: Lawrence Erlbaum Associates.

Resnick, L. B. (1992). From protoquantities to operators: Building mathematical competence on a foundation of everyday knowledge. In G. Leinhardt, R. Putnam \& R. A. Hattrup (Eds), Analysis de arithmetic for mathematics teaching (pp. 373-429). Hillsdale, NY: Lawrence Erlbaum Associates. 
Schliemann, A. D., Carraher, D. W., Brizuela, B. M., Earnest, D., Goodrow, A., Lara-Roth, S. et al. (2003). Algebra in elementary school. In N. Pateman, G. Dougherty \& J. Zilliox (Eds.), Proceedings of the $27^{\text {th }}$ Conference of the International Group for the Psychology of Mathematics Education and the $25^{\text {th }}$ Conference of Psychology of Mathematics Education North America (Vol. 4, pp. 127-134). Honolulu, HI: University of Hawaii.

Stallings, L. (2000). A Brief History of Algebraic Notation. School, Science and Mathematics, $100(5), 230$.

Steffe, L. \& Thompson, P. W. (2000). Teaching experiment methodology: underlying principles and essential elements. In A. Kelly \& R. Lesh (Eds.), Handbook of research design in mathematics and science education (pp. 267-306). Mahwah: NJ: LEA.

Stephens, M. (2006). Describing and exploring the power of relational thinking. In P. Grootenboer, R. Zevenbergen \& M. Chinnappan (Eds.), Proceedings of the 29th annual conference of the MERGA (pp. 479-486). Canberra: MERGA.

Van Ameron, B. A. (2002). Reinvention of early algebra. Developmental research on the transition form arithmetic to algebra. $\mathrm{U}^{\circ}$ trecht: $\mathrm{CD}-\beta$ Press \& Center for Science and Mathematics Education.

Vergnaud, G. (1988). Long terme et court terme dans l'apprentissage de l'algèbre. In C. Laborde (Ed.), Actes du premier colloque franco-allemand de didactique des mathematiques et de l'informatique (pp. 189-199). Paris: La Pensée Sauvage.

Warren, E. (2003).Young children's understanding of equals: a longitudinal study. In N. Pateman, G. Dougherty \& J. Zilliox (Eds.), Proceedings of the $27^{\text {th }}$ Conference of the International Group for the Psychology of Mathematics Education and the $25^{\text {th }}$ Conference of Psychology of Mathematics Education North America (Vol. 4, pp. 379387). Honolulu, HI: University of Hawaii.

Wheeler, R. F. (1981). Rethinking Mathematical Concepts. Chichester: Ellis Horwood Limited. 